\title{
Thermo-Oxidation of Tokamak Carbon Dust
}

\section{$13^{\text {th }}$ International Conference on Fusion Reactor Materials}

J. W. Davis

B. W. N. Fitzpatrick

J. P. Sharpe

A. A. Haasz

U.S. Department of Energy

National Laboratory

operated by

Battelle Energy Alliance

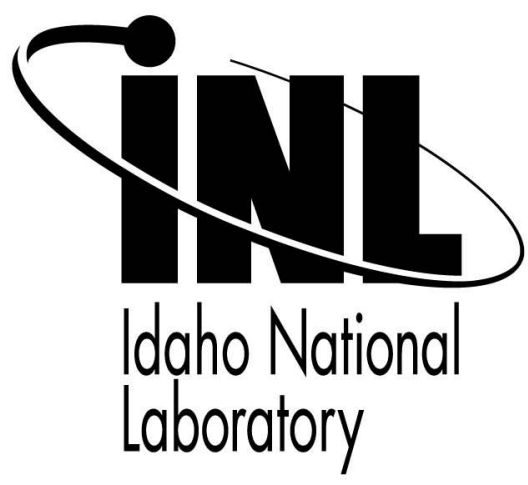

This is a preprint of a paper intended for publication in a journal or proceedings. Since changes may be made before publication, this preprint should not be cited or reproduced without permission of the author. This document was prepared as an account of work sponsored by an agency of the United States Government. Neither the United States Government nor any agency thereof, or any of their employees, makes any warranty, expressed or implied, or assumes any legal liability or responsibility for any third party's use, or the results of such use, of any information, apparatus, product or process disclosed in this report, or represents that its use by such third party would not infringe privately owned rights. The views expressed in this paper are not necessarily those of the United States Government or the sponsoring agency. 


\title{
Thermo-Oxidation of Tokamak Carbon Dust
}

\author{
J.W. Davis ${ }^{1}$, B.W.N. Fitzpatrick ${ }^{1}$, J.P. Sharpe ${ }^{2}$ and A.A. Haasz ${ }^{1}$ \\ ${ }^{1}$ University of Toronto Institute for Aerospace Studies, 4925 Dufferin St., Toronto, ON, Canada, M3H 5T6 \\ 2 INL Fusion Safety Program, 2525 Fremont Dr., Idaho Falls, ID, USA, 83415-3860
}

\begin{abstract}
The oxidation of dust and flakes collected from the DIII-D tokamak, and various commercial dust specimens, has been measured at $350{ }^{\circ} \mathrm{C}$ and $2.0 \mathrm{kPa} \mathrm{O}$ pressure. Following an initial small mass loss, most of the commercial dust specimens showed very little effect due to $\mathrm{O}_{2}$ exposure. Similarly, dust collected from underneath DIII-D tiles, which is thought to comprise largely Grafoil ${ }^{\mathrm{TM}}$ particulates, also showed little susceptibility to oxidation at this temperature. However, oxidation of the dust collected from tile surfaces has led to $\sim 18 \%$ mass loss after 8 hours; thereafter, little change in mass was observed. This suggests that the surface dust includes some components of different composition and/or structure - possibly fragments of codeposited layers. The oxidation of codeposit flakes scraped form DIII-D upper divertor tiles showed an initial $25 \%$ loss in mass due to heating in vacuum, and the gradual loss of $30-38 \%$ mass during the subsequent 24 hours exposure to $\mathrm{O}_{2}$. This behavior is significantly different from that observed for the oxidation of thinner DIII-D codeposit specimens which were still adhered to tile surfaces, and this is thought to be related to the low deuterium content $(\mathrm{D} / \mathrm{C} \sim$ $0.03-0.04)$ of the flakes.
\end{abstract}

\section{Corresponding Author: J. W. Davis}

Email: jwdavis@starfire.utias.utoronto.ca 


\section{Introduction}

Dust is generally recognized as an issue for future fusion reactors due to the potential impact of dust on device safety and operational performance. Dust may be produced in tokamaks through a wide variety of physical mechanisms, and is considered a safety hazard for reasons of chemical activity (explosive hazard [1]), toxicity and possible tritium content. Thus, dust inventory limits have been established to ensure safe operation of ITER [2]. While the carbon dust limit is set at $200 \mathrm{~kg}$, if this dust is composed largely of codeposit flakes, with T/C ratios $\sim 0.1$, then the in-vessel tritium inventory limit of $330 \mathrm{~g}$ will be much more restrictive, possibly limiting the amount of carbon dust to a few $\mathrm{kg}$. The nature of the dust and the procedures available to remove it will depend greatly on the composition and creation mechanism.

Recent efforts have been made to characterize and begin to understand the origin of dust in current plasma machines $[3,4]$. However, it is understood that the nature of the dust created in ITER may be significantly different from that in current tokamaks, as the much greater duty cycle is likely to increase the fraction of codeposit flakes [5]. Procedures proposed for the removal of dust from ITER include mechanical intervention, such as liquid washing [6], or vibratory conveyors [6,7]. In the case of carbon dust, however, it may be possible to remove some or all of the dust by utilizing chemical reactions with oxygen to produce volatile molecules which may be removed from the vacuum vessel by the vacuum pumps. The objective of the present study is to assess the effectiveness of thermo-oxidation for the removal of a variety of dust materials.

Previous measurements on the oxidation of codeposit flakes from TFTR were reported in [5] for a sample of flakes which was heated in air to $773 \mathrm{~K}$ and the release of tritium atoms was detected. Oxidation is also being used in the JET active gas handling facility to recover tritium from dust and flakes removed from the tokamak [8]. In both cases, the temperatures involved are much higher than would be available for in-vessel treatment of dust in current or nextgeneration tokamaks. The oxidation of codeposits from various tokamak tiles has been measured extensively [e.g., 9,10]; in these cases the codeposits were still adhered to specimens cut from the tiles. Codeposits removed from the DIII-D divertor were found to oxidize readily at temperatures of $\sim 350{ }^{\circ} \mathrm{C}$ and $2-20 \mathrm{kPa} \mathrm{O}$ pressure, provided the boron impurity content was less than a few \%. (Boron is introduced into DIII-D by periodic boronizations.) However, for films containing a large fraction of boron, oxidation was not very effective [11].

In the current experiments, we have studied the oxidation of a variety of commercial carbon dusts and of two sets of dust particles collected from the DIII-D tokamak following the $2005{ }^{13} \mathrm{C}$ experiment [12]. In addition, codeposit flakes scraped from DIII-D upper divertor tiles in September 2007 were also tested.

\section{Experiment}

\subsection{Specimens}

\subsubsection{Commercial carbon dust specimens}

Table 1 provides a list and the basic sizing information of the five commercial dust specimens used. All commercial dusts were obtained from Sigma Aldrich carbon nanopowder 
products. Associated product numbers are listed in Table 1. The particle sizes of the specimens ranged from $\sim 0.7 \mathrm{~nm}$ to $<20 \mu \mathrm{m}$.

\subsubsection{Dust collected from DIII-D (2005)}

The primary method for collecting particulates from various locations in the DIII-D vacuum vessel is the filtered vacuum technique used extensively in previous dust collection campaigns of other fusion devices [13]. Particulate collection is achieved with the use of a small oil-free vacuum pump connected to a $50 \mathrm{~mm}$ filter housing. A filter of $0.02 \mu \mathrm{m}$ pore size is placed within the housing, and a $6 \mathrm{~mm}$ diameter probe tip is connected for sampling. Various probe lengths are available for surface or deep recess sampling. The volumetric flow rate of the vacuum filter system is $\sim 15 \mathrm{slpm}$ (standard liters per minute), sufficient to entrain loosely bound particles into the flow stream as the probe tip is moved over the sample surface. Samples are collected by placing the probe tip approximately $1 \mathrm{~mm}$ above the surface and sweeping with a velocity of $2 \mathrm{~cm} / \mathrm{s}$. The particles are deposited on the filter substrate, which is later removed for analysis. Upon disassembly in the laboratory, the filter substrate and any particle material not adherent to the substrate are removed from the filter housing, weighed for collected mass, and placed in metal storage tins. The size limit of this collection method corresponds to the filter collection cutoff at $0.02 \mu \mathrm{m}$, although particles of size less than $\sim 0.1 \mu \mathrm{m}$ are generally observed only as components of larger agglomerates.

The current specimens were collected from two types of locations within DIII-D. Specimen DIII-D-1 comprises dust collected from underneath 24 tiles spanning the full poloidal range of locations, at toroidal positions ranging from 125 to $170^{\circ}$. The dust in specimen DIII-D2 was collected from 29 tile surfaces, again, comprising the full poloidal range at a toroidal position of $\sim 20^{\circ}$. In addition, dust from the $30^{\circ}$ neutral beam port, the vacuum pumping port, the bumper limiter, and the RF launcher are also included in specimen DIII-D-2. General sizing information is given in Table 1. Size distribution results were prepared from counting measurements on filters from each collection location, and the specific surface area measurements were performed with a Micromeritics ASAP 2120 surface area analysis instrument.

\subsubsection{DIII-D flakes}

Exfoliating deposits from the upper divertor tiles (toroidal position $15^{\circ}$ ) were removed using a plastic scraper. Only the loose parts of the deposits were removed. Collected flakes were typically 1-6 $\mathrm{mm}^{2}$ in area, with an estimated thickness of $\sim 50 \mu \mathrm{m}$. XPS analysis of one of the flakes indicated that the composition was primarily carbon, with a small amount of boron impurity; $\mathrm{B} /(\mathrm{B}+\mathrm{C}) \sim 4.7 \%$. While the composition of these deposits is similar to those found on lower divertor tiles in DIII-D [9], they are more than 10 times thicker than those previously studied [9], and may have been formed under unusual operating conditions, and their formation may be related to a nearby gas inlet.

\subsection{Oxidation Facility and Procedure}

Oxidation was performed in the facility shown schematically in Figure 1. Dust and flake specimens were placed in open stainless steel boxes approximately $2 \mathrm{~cm}$ square and $1 \mathrm{~cm}$ tall. The specimens were then installed in the vacuum test chamber, which, enclosed within baking 
panels, was heated to $350{ }^{\circ} \mathrm{C}$. The temperature was measured using a copper-constantan thermocouple fixed to the chamber's exterior. When the system was at the desired temperature, pure oxygen gas was admitted to the test chamber to a pressure of $2.0 \mathrm{kPa}(\sim 15 \mathrm{Torr})$. The pressure was measured by a convectron gauge calibrated for oxygen gas. A leak valve supplied a constant flow of oxygen into the chamber, balancing the flow of $\mathrm{O}_{2}$ and oxidation products through the pumping valve - thus maintaining a relatively constant pressure in the chamber.

Specimens were oxidized in time increments ranging from an initial period of $1 / 2$ hour, to periods as long as 8 hours. Cumulative oxidation times ranged from 8 to 24 hours. Specimens were weighed ex-situ using a Mettler AG285 mass balance, with a precision of $0.01 \mathrm{mg}$. Specimens were weighed prior to being placed in the vacuum system, following heating to 350 ${ }^{\circ} \mathrm{C}$ for 2-3 hours without oxygen, and following each oxidation increment. Multiple measurements (typically 3 or 4 ) were made at each weighing step. The reproducibility observed for repeat weighings was $\sim 0.1 \mathrm{mg}$.

\section{Results and Discussion}

\subsection{Commercial Dust Specimens}

The mass change of the five commercial dust specimens as a function of oxidation time is shown in Figure 2. For four of the five specimens, the mass change is characterized by a small $(<2 \%)$ decrease during the first $1 / 2$ hour of oxidation, followed by no further changes for total oxidation periods up to 24 hours. Our interpretation is that a small component of the specimens is more susceptible to oxidation, either through small size or differing structure. The specimen with the smallest weight change, the graphite powder, was also the specimen with the largest dust particle size. It is noted that handling of the specimen boxes during the course of weighing inevitably led to the shifting of the dust within the boxes, helping to ensure that all dust particles would be exposed to oxygen.

In the case of the Fullerene specimen, which was $99.9 \%$ pure, we observe a quasiexponential decrease in mass, affecting $\sim 3 \%$ of the particles in the specimen. Due to agglomeration of the C-60 molecules, Fullerene has a wide size distribution. We might expect the rate of oxidation to vary inversely with the size of the agglomerates, since smaller particles have a higher surface area to mass ratio. In this case, the initial oxidation would be primarily due to the smaller particles. As these smaller particles are removed by oxidation, their proportion of the total specimen would decrease, and the oxidation rate would slow. This hypothesis is consistent with the observed exponential decrease in mass.

\subsection{DIII-D dust}

The mass change of specimen DIII-D-1 as a function of oxidation time is shown in Figure 3. Following 8 hours of oxidation, less than $1 \%$ of the dust was oxidized. This is consistent with the suggestion that dust collected from beneath the tiles originated primarily from the Grafoil sheets used as a thermally conducting compliant layer behind the tiles [14]. Previous experiments have shown that the oxidation of various forms of solid graphite results in very little mass loss at $350^{\circ} \mathrm{C}[15,16]$. Recent oxidation results for pieces of Grafoil also did not show measurable mass loss [17]. 
The oxidation response of specimen DIII-D-2 is shown in Figure 4. During the first 8 hours, an $18 \%$ decrease in mass was observed, with no further loss in mass during continued oxidation. This suggests that there may be several components to the specimen, with some, such as codeposit flakes, being more susceptible to oxidation.

The apparent exponential-decay of the two DIII-D dust specimens might be attributed, as with Fullerene, to their wide size distributions. The geometric mean diameters of specimens DIII-D-1 and DIII-D-2 were 5.15 and $2.50 \mu \mathrm{m}$, respectively, and their geometric standard deviations were 2.52 and 3.32 , respectively.

\subsection{DIII-D flakes}

Unlike most of the dust specimens, the DIII-D codeposit flakes lost a significant fraction of their mass, $\sim 25 \%$, simply by heating in vacuum to $350{ }^{\circ} \mathrm{C}$. By comparison, the mass loss following heating-only for the commercial dust specimens was $<1 \%$, and for DIII-D- $1 \sim 4 \%$. It was not possible to determine the mass loss due to heating only for specimen DIII-D-2, as a solvent was used to wash the dust into the test box, and evaporation of the solvent masked any changes to the specimen mass.

As shown in Fig. 5, the two codeposit flake specimens oxidized experienced a small ( $1 \%$ ) increase in mass following the first $1 / 2$ hour of oxidation. However, there was a total of $30 \%$ (specimen 1) or $38 \%$ (specimen 2) loss in mass over the subsequent $23 \frac{1}{2}$ hours of $\mathrm{O}_{2}$ exposure. The initial gain in mass might be attributed to the formation of boron oxide via oxidation of the boron impurity in the flakes. However the $<5 \%$ B content, based on previous findings [9], is not expected to block the oxidation of the flakes. Therefore, some other factor, eg., deposit structure, may be responsible for the less than anticipated flake oxidation rate.

Thermal desorption spectroscopic measurements performed on two individual flakes (which were not oxidized), together with mass measurements, give estimated $\mathrm{D} / \mathrm{C}$ ratios of $~$ $0.03-0.04$. Thus, the properties of these flakes may be somewhat different from the properties of the DIII-D codeposits previously studied [9]. The latter were adhered to the tile substrate during oxidation and their deuterium content was about $0.1 \mathrm{D} / \mathrm{C}$ [9].

\section{Summary}

Thermo-oxidation of most of the carbon dust specimens tested in this study has been shown to be ineffective in removing the dust at a temperature of $\sim 350{ }^{\circ} \mathrm{C}$. There is, however, some indication that some relatively small dust particles are being oxidized. The low reactivity to $\mathrm{O}_{2}$ at this temperature is consistent with the results on the oxidation of a variety of solid graphites [15-17].

The dust and flake specimens taken from DIII-D behaved in a somewhat similar manner, depending on the composition, collection location and production mechanism. For dust collected from tile surfaces, which may have been produced through various mechanical and plasmasurface interaction mechanisms, approximately $20 \%$ of the dust was oxidized in 8 hours. For dust collected from beneath DIII-D tiles, less than $1 \%$ of the dust was oxidized, consistent with the hypothesis that this dust largely originated from the Grafoil sheets used as thermal mounts for the tiles. Codeposit flakes, with $\mathrm{D} / \mathrm{C} \sim 0.03-0.04$, scraped from upper divertor tiles of DIII$\mathrm{D}$ first experienced a small increase in mass, followed by a steady decline, ultimately resulting in a $30-38 \%$ decrease in mass after 24 hours of total $\mathrm{O}_{2}$ exposure. 
These results suggest that certain forms of dust might reasonably be oxidized at temperatures within reach of ITER. However, further research is needed for assessing the effectiveness of thermo-oxidation as a tool for dust removal in ITER.

\section{Acknowledgements}

We thank Dr. Dmitry Rudakov (UCSD) and Yarong Mu (University of Toronto) for carefully removing the codeposit flake specimens from DIII-D for our experiments, Dr. Phil West (GA) and Adam McLean (University of Toronto) for helping with arrangements for dust collection, and Dr. Peter Brodersen at Surface Interface Ontario, University of Toronto, for performing the XPS analysis. We also thank Oscar Zhe Tian (University of Toronto) for making the TDS measurements of the DIII-D codeposit flakes. The research performed at the University of Toronto was supported by the Natural Sciences and Engineering Research Council of Canada. We express our thanks to Charles Perez for his diligent work in commissioning the experimental facility.

\section{References:}

[1] A. Denkevits, S. Dorofeev, Fus. Eng. Design, 75-79 (2005) 1135.

[2] Generic Site Safety Report Vol. III, Radiological and Energy Source Terms. ITER Report G 84 RI 3 01-07-13 R1.0

[3] J.P. Sharpe, D.A. Petti, H.-W. Bartels, Fus. Eng. Design 63-64 (2002) 153.

[4] M. Rubel, M. Cecconello, J.A. Malmberg, G. Sergienko, et al., Nucl. Fus. 41 (2001) 1087.

[5] G Federici, CH Skinner, JN Brooks et al., "Plasma-material interactions in current tokamaks and there implications for next step fusion reactors", Nucl. Fusion 41 (2001) 1967.

[6] G.F. Counsell, C.H. Wu, Phys. Scripta T91 (2001) 70.

[7] M. Wykes, G. Counsell, D. McGlinchey, C.H. Wu, Fus. Eng. Design 56-57 (2001) 403.

[8] S. Grünhagen, A. Prvezentsev, P.D. Brennan, P. Camp, et al., "Techniques for tritium recovery from carbon flakes and dust at the JET active gas handling facility", $8^{\text {th }}$ Int. Conf. on Tritium Science and Technology, September 16-21 2007, Rochester, NY.

[9] A.A. Haasz, C.K. Tsui, J.W. Davis and R Ochoukov, Physica Scripta T128 (2007) 55.

[10] C. K. Tsui, A.A. Haasz, J.W. Davis, J.P. Coad, J. Likonen, "Thermo-oxidation of Becontaining codeposits from JET divertor tiles", Nucl. Fusion 48 (2008) 035008.

[11] J.W. Davis, P.B. Wright, R.G. Macaulay-Newcombe, A.A. Haasz, C.G. Hamilton, J. Nucl. Mater. 290-293 (2001) 66.

[12] W.R. Wampler, A.G. McLean, S.L. Allen, N.H. Brooks, J. Nucl. Mater., 363-365 (2007) 72

[13] J.P. sharpe, V. Rohde, A. Sagara, H. Suzuki, et al., J. Nucl. Mater. 313-316 (2003) 455.

[14] K.L. Holtrop, G.L. Jackson, A.G. Kellman, R.L. Lee, M.A. Hollerbach, J. Vac. Sci. Technol. A12 (1994) 1269.

[15] J.W. Davis, C.G. Hamilton, A.A. Haasz, J. Nucl. Mater. 288 (2001) 148

[16] M. Balden, K.U. Klages, W. Jacob, J. Roth, J. Nucl. Mater. 341 (2005) 31

[17] B.W.N. Fitzpatrick, University of Toronto, unpublished results, 2007 
Table 1: Summary of dust properties.

\begin{tabular}{|c|c|c|}
\hline Туре & Sizing Information & Origin \\
\hline $\begin{array}{l}\text { C-60 Fullerene } 99.9+\% \\
\text { CAS 99685-96-8 }\end{array}$ & $\begin{array}{l}\text { Size: } 0.7 \mathrm{~nm} \\
\text { Surf. Area: } 120 \mathrm{~m}^{2} / \mathrm{g}\end{array}$ & $\begin{array}{l}\text { Commercial dust- Sigma } \\
\text { Aldrich Prod. No. } 572500 .\end{array}$ \\
\hline $\begin{array}{l}\text { Diamond Nanopowder } 97+\% \\
\text { CAS } 7782-40-3\end{array}$ & $\begin{array}{l}\text { Size: }<10 \mathrm{~nm} \\
\text { Surf. Area: } 200-450 \mathrm{~m}^{2} / \mathrm{g}\end{array}$ & $\begin{array}{l}\text { Commercial dust- Sigma } \\
\text { Aldrich Prod. No. } 636428 .\end{array}$ \\
\hline $\begin{array}{l}\text { Carbon Nanopowder } 99+\% \\
\text { CAS } 7440-44-0\end{array}$ & $\begin{array}{l}\text { Size: }<50 \mathrm{~nm} \\
\text { Surf. Area: } \sim 100 \mathrm{~m}^{2} / \mathrm{g}\end{array}$ & $\begin{array}{l}\text { Commercial dust- Sigma } \\
\text { Aldrich Prod. No. } 633100 .\end{array}$ \\
\hline $\begin{array}{l}\text { Graphite Powder } \\
\text { CAS } 7782-42-5\end{array}$ & $\begin{array}{l}\text { Size: }<20 \mu \mathrm{m} \\
\text { Surf. Area: } 8 \mathrm{~m}^{2} / \mathrm{g}\end{array}$ & $\begin{array}{l}\text { Commercial dust- Sigma } \\
\text { Aldrich Prod. No. } 282863 .\end{array}$ \\
\hline $\begin{array}{l}\text { Carbon Nanotubes, } \\
\text { Multiwalled }\end{array}$ & $\begin{array}{l}\mathrm{OD}=40-70 \mathrm{~nm} \\
\mathrm{ID}=5-40 \mathrm{~nm} \\
\text { length }=0.5-2 \mu \mathrm{m} \\
\text { Surf. Area: N/A }\end{array}$ & $\begin{array}{l}\text { Commercial dust- Sigma } \\
\text { Aldrich Prod. No. } 636843 \text {. }\end{array}$ \\
\hline DIII-D Dust Specimen 1 & $\begin{array}{l}\text { Size: } \quad \mathrm{CMD}^{1}-6.24 \mu \mathrm{m} \\
\quad \mathrm{GSD}^{2}-2.52 \\
\text { Surf. Area: } 5.2 \mathrm{~m}^{2} / \mathrm{g}\end{array}$ & Collected from beneath tiles \\
\hline DIII-D Dust Specimen 2 & $\begin{array}{l}\text { Size: } \quad \mathrm{CMD}^{1}-2.44 \mu \mathrm{m} \\
\mathrm{GSD}^{2}-3.32 \\
\text { Surf. Area: } 0.50 \mathrm{~m}^{2} / \mathrm{g}\end{array}$ & Collected from tile surfaces \\
\hline DIII-D Flakes & $\begin{array}{l}\text { N/A. Flake size determined } \\
\text { by method of scraping }\end{array}$ & Scraped from tile surfaces \\
\hline
\end{tabular}

${ }^{1}$ CMD: Count Mean Diameter; ${ }^{2}$ GSD: Geometric Standard Deviation 
Figure Captions:

Figure 1: Schematic of oxidation facility at the University of Toronto.

Figure 2: Oxidation results for the commercial dust specimens; see Table I for size information. As indicated in the text, three or four measurements were made at each weighing step, however, in most cases shown here, the reproducibility of the measurements $(\sim 0.1 \mathrm{mg})$ is much smaller than the scale of the figure.

Figure 3: Oxidation results for Specimen DIII-D-1; dust collected from beneath DIII-D tiles (mean diameter: $6.24 \mu \mathrm{m}$ ).

Figure 4: Oxidation results for Specimen DIII-D-2; dust collected from DIII-D tile surfaces (mean diameter: $2.44 \mu \mathrm{m}$ ).

Figure 5: Oxidation results for DIII-D codeposit flakes scraped from the surface of DIII-D upper divertor tiles (typical size: $1-6 \mathrm{~mm}^{2}$ area, $\sim 50 \mu \mathrm{m}$ thick). 
Figure 1

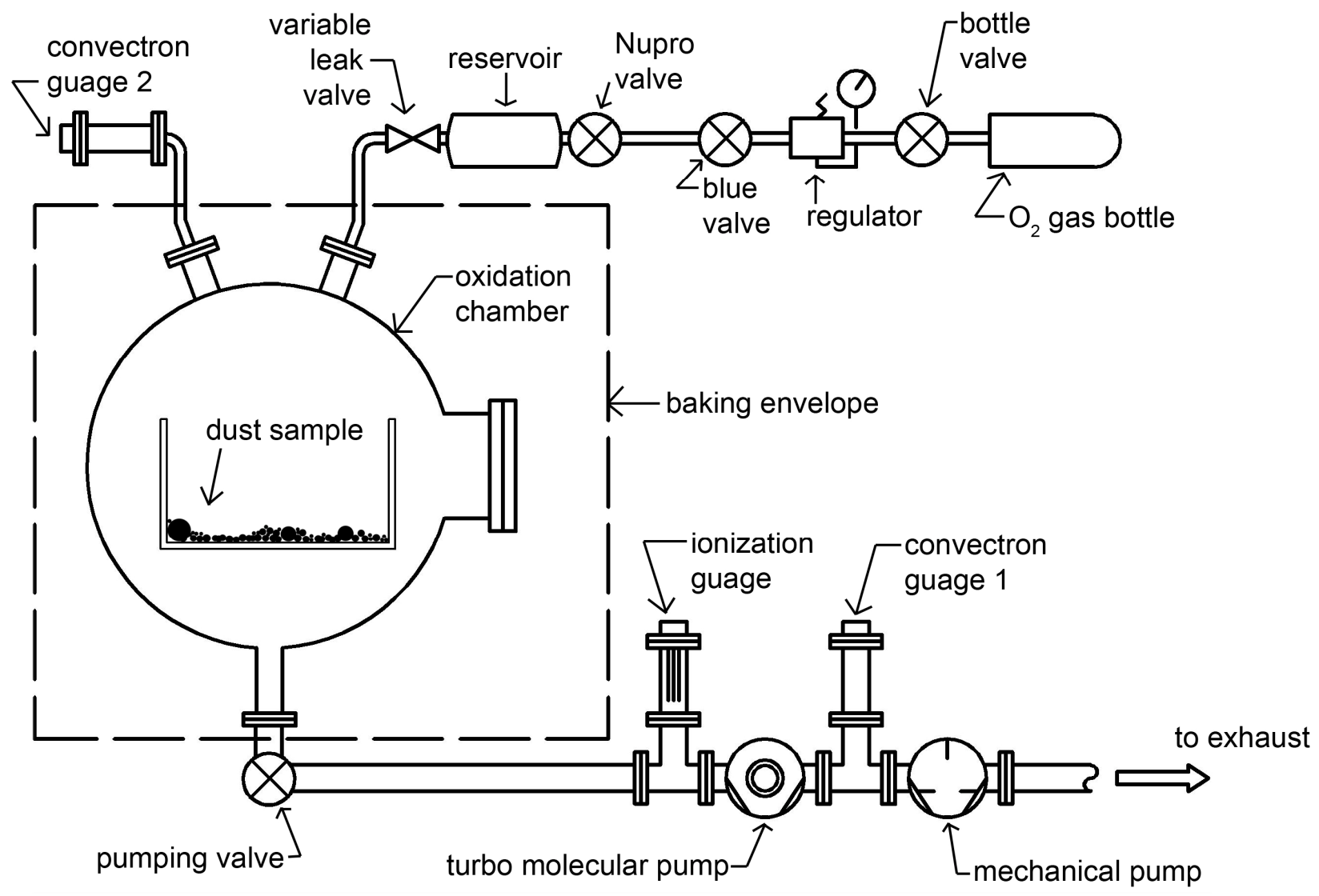


Figure 2:

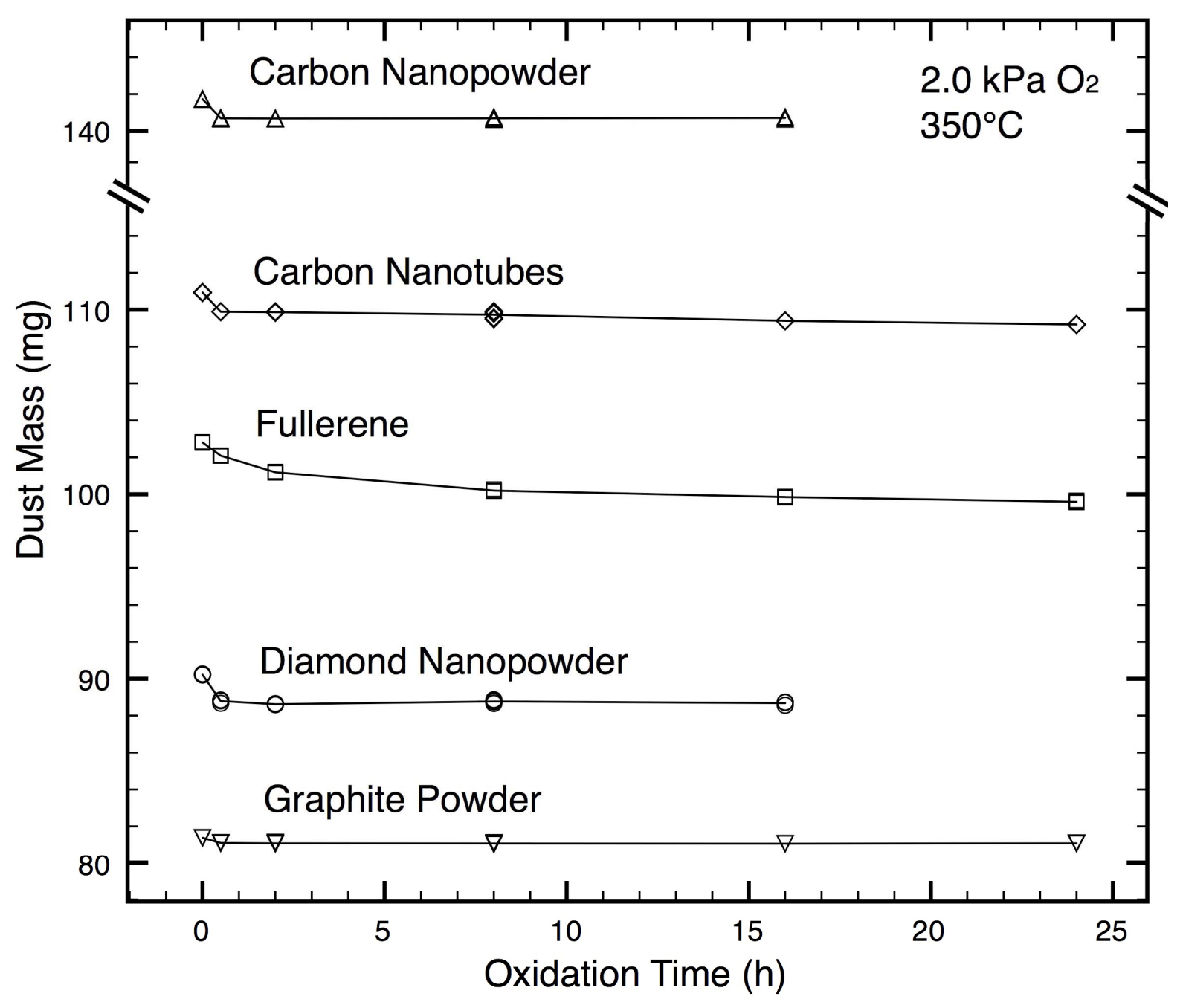


Figure 3

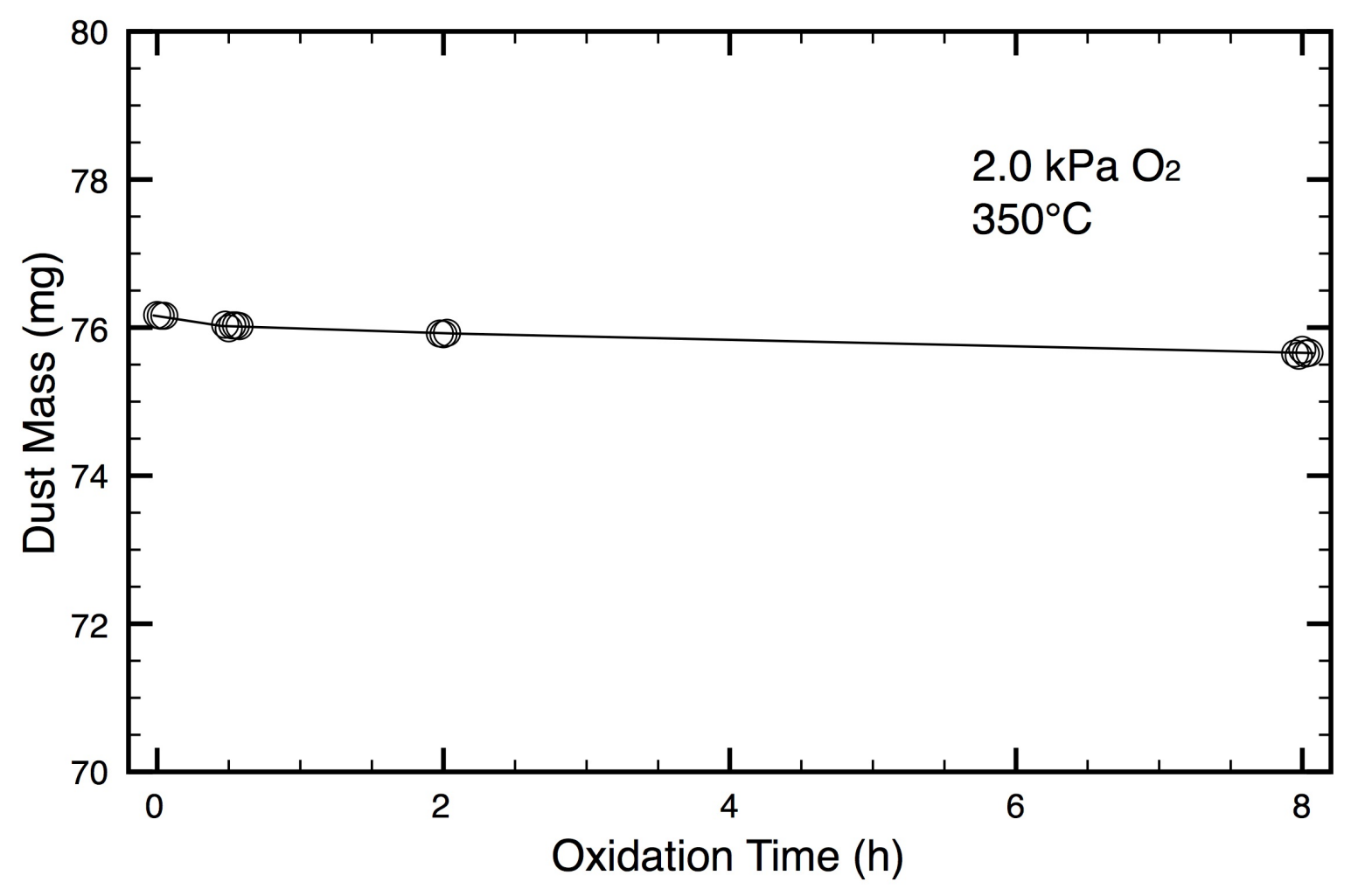


Figure 4

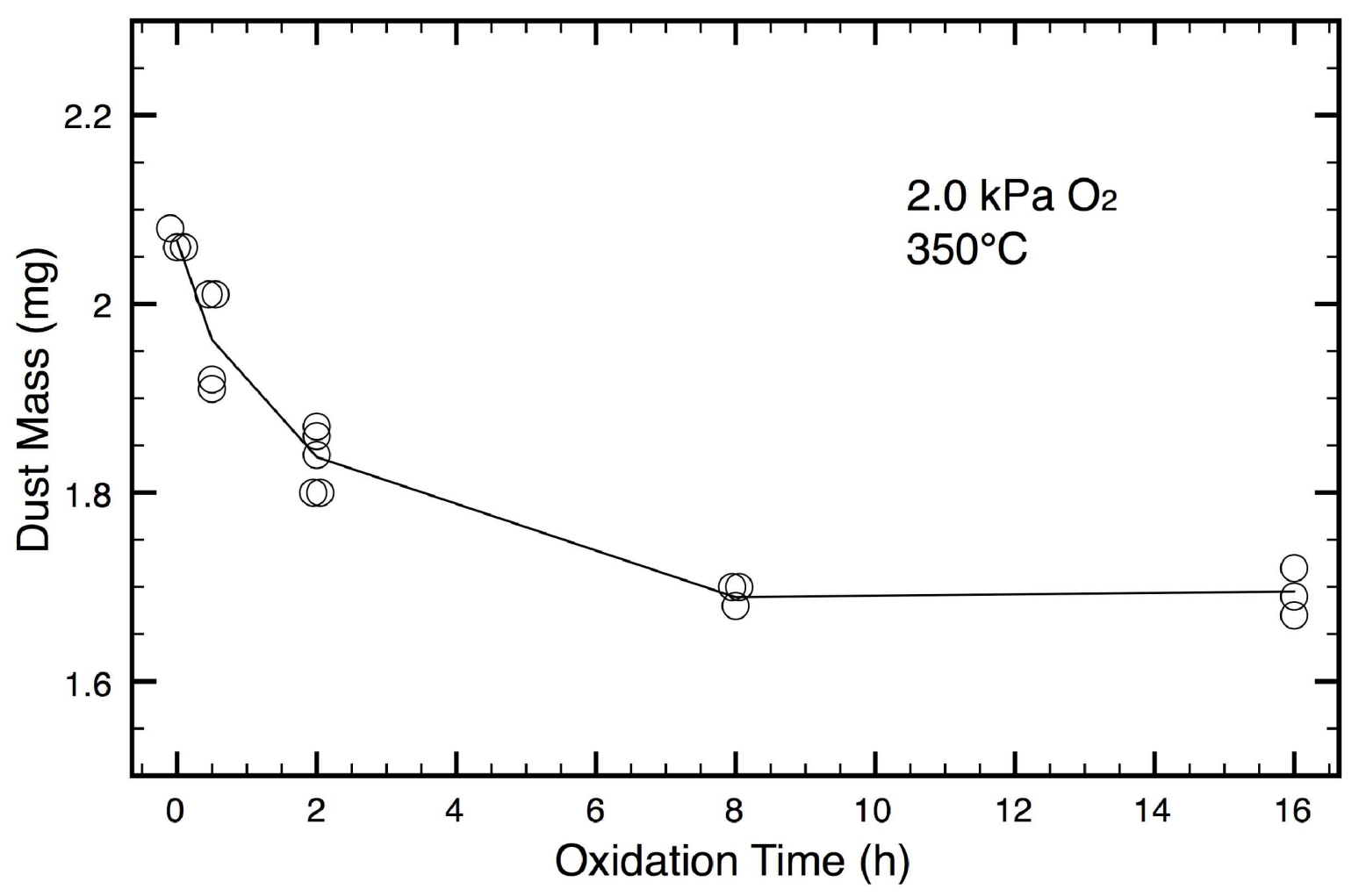


Figure 5

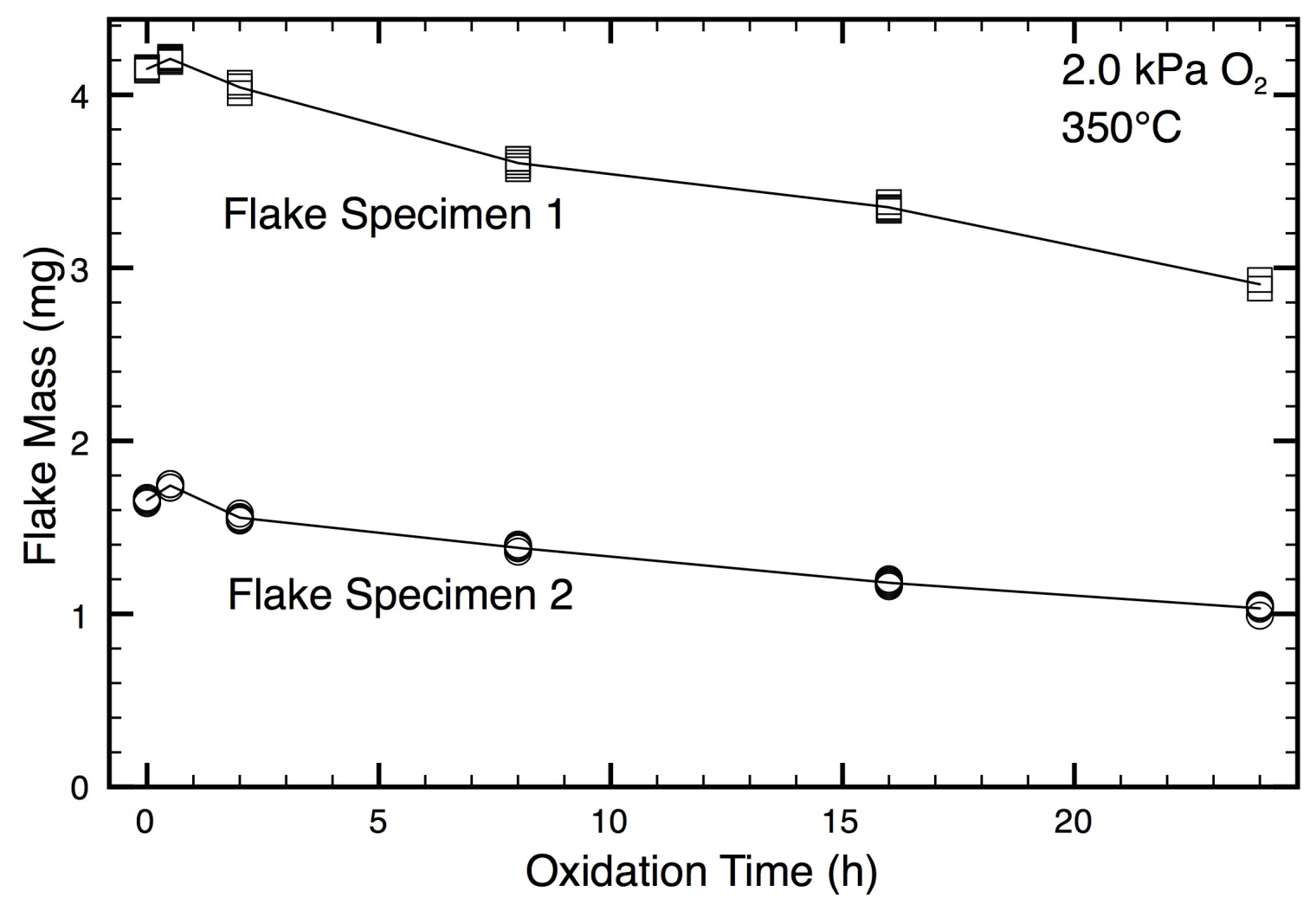

